\title{
PRÁtICAS DE GESTÃo DE ESCOLAS PÚBLICAS ESTADUAIS DE PORTO ALEGRE PROTAGONISMOS NA GESTÃO ESCOLAR
}

\author{
Andreana Catarina Haas Reichert
}

O presente estudo problematiza quais conhecimentos, habilidades $\mathrm{e}$ atitudes dos gestores escolares qualificam a gestão escolar democrática. Desde a Constituição Federal de 1988, tem-se a premissa da gestão escolar democrática como uma busca da educação de qualidade. Analisar a gestão escolar pública, visando a identificar as competências que qualificam as práticas de gestão da equipe diretiva, conhecer a realidade dos gestores quanto à efetivação da gestão escolar democrática, assim como, desvendar o protagonismo destes, no seu papel político, pedagógico e social na construção de uma educação de qualidade. Considerado o contexto das políticas públicas para a Educação Básica, por meio do estudo das Leis, Diretrizes e Planos das políticas públicas frente aos desafios da educação brasileira, surge a indagação: Como as mesmas se concretizam nas escolas públicas de Educação Básica? Quais ações de gestão estão sendo desenvolvidas nas escolas com vistas à educação de qualidade? De que forma as metas propostas nos planos, nas diretrizes e nas estratégias para a educação brasileira estão sendo assumidas no cotidiano das práticas dos gestores das instituições escolares de Educação Básica?

A gestão surgiu quando, após a revolução industrial, os profissionais decidiram buscar soluções para problemas que não existiam antes, usando vários métodos de ciências, para administrar os negócios da época, o que deu início à ciência da administração, pois se fizeram necessários o conhecimento e a aplicação de modelos e técnicas administrativas (PARO, 2012). A gestão é um ramo das ciências humanas, pois trata com grupo de pessoas, procurando manter a sinergia entre elas, a estrutura e os recursos existentes. No caso da gestão escolar, contempla os processos da gestão administrativa, dos recursos materiais, da estrutura física e da gestão de pessoas: professores, alunos e comunidade educativa. A gestão escolar democrática, mencionada por (CURY, 2002), tem sua origem etimológica da palavra gestão: "provém do verbo latino gero, gessi, gestum, gerere e significa: levar sobre si, carregar, chamar a si, executar, exercer, gerar. 
Contempla o ato que traz, em si e dentro de si, algo novo, diferente: um novo ente."

Vivem-se constantes mudanças, locais e globais, que requerem um novo paradigma quanto à concepção da educação, de escola, de relação escola/sociedade e consequentemente da gestão escolar. As mudanças necessárias à melhoria da educação brasileira demandam um novo enfoque para a gestão escolar e não apenas uma mudança terminológica com uma atitude pautada em transformações nas relações de poder, de práticas, da organização escolar em si, com uma construção de participação e compromisso com a realidade e relação das pessoas (LÜCK, 2000). Cabe situar a gestão: onde existe uma instituição, uma empresa, uma entidade social de pessoas, a ser gerida ou administrada, tem-se gestão. Nesse caso, pode-se estender o conceito para a gestão escolar. Conforme (FERREIRA, 2007, p. 36):

Gestão é administração, é tomada de decisão, é organização, é direção. Relaciona-se com a atividade de impulsionar uma organização e atingir seus objetivos, cumprir sua função, desempenhar seu papel. Constitui-se de princípios e práticas decorrentes que afirmam ou desafirmam os princípios que a geram. Estes princípios, entretanto, não são intrínsecos à gestão como a concebia a administração clássica, mas são princípios sociais, visto que a gestão da educação se destina a promoção humana.

Cabe analisar a gestão escola na concepção de escola como uma organização peculiar, que tem tarefas sociais e éticas, com um caráter profundamente democrático (DEMO, 2012). O domínio do processo de trabalho do gestor escolar requer qualificações táticas implícitas e não formalizadas (LIBÂNEO, 2013) necessários, e que na atualidade, observam-se novos atributos que estão presentes no processo de trabalho: autonomia, responsabilidade, comunicação e polivalência. (RAMOS, 2001).

Concebe-se a gestão escolar como aquela que considera os processos administrativos e pedagógicos, interagindo entre si e sintonizando-os com vistas a ações estratégicas cunhadas ao objetivo maior da escola em desenvolver práticas de ensino que promovam a formação integral de seus sujeitos. A escola deve desenvolver um trabalho coletivo e participante, tendo como pressuposto que o trabalho que se realiza com a participação responsável de cada um dos sujeitos envolvidos é o que atende de forma mais efetiva às necessidades concretas da sociedade em que vivemos (RIOS, 2011). E ao referir-se o termo competência, o concebe como o saber fazer bem, o necessário e o desejável no espaço da 
profissão.

Quanto à qualidade na educação, termo recorrente nos discursos, e constituído pela polissemia de definições, considera-se no estudo em pauta, a dimensão da qualidade da educação, como prática social, portanto um ato político, com responsabilidade ética e técnica para a promoção dos sujeitos a ela confiados. Traz-se presente a definição de (SILVA, 2009, P.225) para a escola de qualidade social:

[...] aquela que atenta para os elementos e dimensões socioeconômicas e culturais que circundam o modo de viver e as expectativas das famílias e dos estudantes em relação à educação; que busca compreender as políticas governamentais, os projetos sociais e ambientais em seu sentido político, voltados para o bem comum; uma escola que luta por financiamento adequado, pelo reconhecimento social e valorização dos trabalhadores em educação; que transforma todos os espaços físicos em lugar de aprendizagens significativas e de vivências efetivamente democráticas.

A pesquisa realizada em três escolas públicas estaduais de Porto Alegre foi definida pela significativa absorção das matrículas nas instituições públicas estaduais, conforme Censo Escolar da Educação Básica 2013 (RIO GRANDE DO SUL, 2014). A rede pública estadual atende a $44 \%$ dos alunos e estes estão concentrados em $25 \%$ dos estabelecimentos de ensino na cidade de Porto Alegre. Das 305.153 (trezentos e cinco mil, cento e cinquenta e três) matrículas, 48,5\% (quarenta e oito e meio por cento) delas concentram-se nas escolas públicas estaduais. As escolas públicas estaduais do município representam 25\% (vinte e cinco por cento) das instituições de Educação Básica do município. Constata-se que a gestão destas instituições tem relevância no compromisso com o Índice de desempenho da Educação Básica (IDEB1) no cenário da educação do Estado do Rio Grande do Sul. No período de maio a julho de 2014, realizou-se a pesquisa qualitativa, com entrevistas semiestruturadas, com três equipes diretivas de escolas públicas estaduais. Foram entrevistados três diretores, seis vice-diretores e dois coordenadores pedagógicos das três escolas definidas, pelos critérios de porte médio, em média 700 alunos, diferentes bairros do município e desempenho progressivo no IDEB.

\footnotetext{
1 O Ideb foi criado pelo Inep em 2007, em uma escala de zero a dez. Sintetiza dois conceitos igualmente importantes para a qualidade da educação: aprovação e média de desempenho dos estudantes em língua portuguesa e matemática. O indicador é calculado a partir dos dados sobre aprovação escolar, obtidos no Censo Escolar, e médias de desempenho nas avaliações do Inep, o Saeb e a Prova Brasil.
} 
Para a análise de conteúdo, interpretação dos discursos e observações realizadas nos contatos com as escolas e nas entrevistas com as equipes, utilizouse da fundamentação teórica de (BARDIN, 1977) e de (MORAES, 2007). O período da realização das entrevistas foi concentrado, três meses, com o objetivo de captar os discursos da equipe diretiva, num mesmo contexto, considerado o cotidiano da escola que é permeado de momentos e projetos que podem interferir na disponibilidade de seus profissionais. Ainda como elemento de análise, utilizou-se o diário de bordo, a fim de pontualmente registrar percepções, falas, contextos, com o objetivo de interpretação e compreensão fidedignas.

Outro aspecto que motivou a escolha por pesquisar gestão escolar pública diz respeito à eleição da equipe diretiva nas escolas públicas estaduais do Estado. Conforme a Lei $n^{\circ} 13.992 / 12$, no seu art. $7^{\circ}$ : "Os Diretores e os ViceDiretores das escolas públicas estaduais serão indicados pela comunidade escolar de cada estabelecimento de ensino, mediante votação direta por meio de chapa." (RIO GRANDE DO SUL, 2012). Considera-se que os docentes que se candidatam à função de diretor e vice-diretor, são sujeitos conhecedores da realidade da escola que pretendem dirigir e são legitimados pela comunidade escolar, por meio da eleição. Observaram-se aspectos da identidade de cada escola pesquisada, um pouco de sua história e da sua cultura escolar, buscando captar as características emergentes do cotidiano de cada escola e apreender dos discursos dos gestores pesquisados aspectos que constituem a identidade de cada uma das escolas onde atuam as equipes pesquisadas.

A entrevista semiestruturada contemplou questões norteadoras, direcionadas ao objeto de estudo, como: trajetórias profissionais, inquietudes, sugestões e proposições, formação continuada dos gestores, principais processos administrativos e pedagógicos da escola, autonomia, suporte da Secretaria de Educação, participação do Conselho escolar, percepção de como os gestores pesquisados se reconhecem na comunidade, evidências quanto à efetivação das políticas públicas, 0 processo de eleição, o compromisso com as avaliações/resultados, entre outros.

A realidade dos gestores escolares quanto à efetivação da gestão escolar democrática apresenta novas concepções quanto à gestão escolar. Os gestores pesquisados referem-se às equipes de trabalho, destacam a validade da participação efetiva dos professores nos momentos de planejamento de projetos, 
com a participação dos alunos e da comunidade em geral, oportunizando o comprometimento com os projetos desenvolvidos, com participação e significado, constituindo assim aprendizagens, revelando uma nova concepção de gestão participativa. Destacam que a participação de professores, alunos e comunidade em geral, necessita permanentemente ser construída e motivada pela equipe gestora.

$\mathrm{Na}$ perspectiva da gestão democrática, reconhece-se nas equipes diretivas a legitimidade desses indivíduos - sujeitos - que atuam e que pertencem à comunidade escolar. São sujeitos que trazem consigo o desejo de uma escola de qualidade, mesmo com responsabilidades técnicas, pedagógicas e éticas específicas da gestão, desafiam-se com o aporte da docência, deparando-se com limitações técnicas e específicas da área da gestão. Todos os integrantes das equipes pesquisadas partem da docência e almejam formação na gestão escolar, devido às especificidades encontradas. A gestão escolar democrática, no que se refere à eleição da equipe diretiva, demonstra ser um processo consolidado, porém peculiar em cada Escola, considerado seu contexto social, cultural e a comunidade em que está inserida. Há que se considerar que os gestores em exercício foram convidados pelas equipes anteriores a participarem do processo eletivo para assumir o cargo, um passo considerado importante, do ponto de vista dos sujeitos pesquisados, na condução das escolas públicas. Surge uma indagação: do ponto de vista da docência, o que motiva esses professores a assumirem o compromisso com a gestão? Na perspectiva da gestão democrática, são sujeitos que representam interesses de quem? Lembra-se de que esses profissionais docentes foram legitimados pela comunidade à qual pertencem. Quais expectativas trazem? Os eleitos e seus eleitores? Será que existem expectativas? Como essa comunidade assume a gestão democrática?

O compromisso assumido com a efetivação das políticas públicas para a melhoria da educação de qualidade confirma-se pela efetivação dos Programas como: Pacto pela alfabetização na idade certa, Pacto pelo fortalecimento do Ensino Médio, Pronatec, entre outros.

Quanto à assessoria da Secretaria da educação, é unânime por parte dos diretores, que há insuficiência do suporte técnico, administrativo e pedagógico para os devidos encaminhamentos nas Escolas.

Comprometidos com o desempenho competente e compromissado ética e politicamente (LIBÂNEO, 2013) a gestão escolar tem sua essência na forma como 
os sujeitos por ela responsáveis articulam, planejam e efetivam suas práticas gestoras. Percebe-se que além do comprometimento há a necessidade de domínios de conhecimentos técnicos. Há que se investir em formação continuada dos gestores, nas áreas que contemplem conhecimentos específicos da gestão escolar com vistas à competência gestora e seu necessário profissionalismo.

Propõe-se, além da necessidade da profissionalização, o protagonismo do gestor com competências, atitudes e habilidades. Constatou-se que os sujeitos pesquisados almejam o domínio de conhecimentos técnicos da gestão escolar democrática, percebendo que há a necessidade de domínios de conhecimentos para a gestão competente e não somente a sua experiência prática, o seu referencial teórico ou as suas idiossincrasias.

Busca-se uma educação de qualidade, esta deve estar imbricada à participação de todos os atores envolvidos no processo de formação escolar integral. Associado ao termo qualidade apresenta-se o termo democracia. Qualidade em educação concebe a participação e a construção participativa, responsável e, portanto, democrática.

A tessitura do trabalho dos gestores nas escolas consolida-se pela trama possível e necessária que esses profissionais necessitam conhecer e reconhecer. $\mathrm{O}$ educador e, no caso, o gestor escolar, é um sujeito que articula e transita pelos diferentes territórios que constituem a escola. Circula entre alunos, professores, famílias, mantenedora e comunidade em geral. É um profissional que necessita da desenvoltura e da responsabilidade para saber articular os potenciais e desvendar possibilidades, diplomacia e conectividade são atributos importantes ao gestor escolar. A responsabilidade com a gestão perpassa o compromisso ético e técnico que os gestores assumem.

A escola de Educação Básica está desafiada a cumprir sua missão com qualidade e responsabilidade, desenvolvendo seus processos com foco nas questões da aprendizagem e nas questões econômico-financeiras, primando pela sustentabilidade econômica e social. Um compromisso a ser assumido com ética, responsabilidade e autonomia, pelos profissionais da educação, seus professores e gestores, sem perder de vista a identidade da instituição escolar, que por meio da educação escolar, busca desenvolver os sujeitos para o exercício pleno de sua cidadania.

Acredita-se num educador comprometido com a construção de uma 
sociedade justa, democrática, interferindo no real e na organização de relações de solidariedade e não de dominação entre os homens (RIOS, 2011). Para tanto, a ação pedagógico-administrativa requer competências técnicas, pedagógicas e administrativas por parte de seus profissionais, pautadas pela gestão democrática, num exercício contínuo que visa a mobilizar o compromisso individual e coletivo da comunidade educativa, na promoção de uma educação de qualidade.

Provisoriamente conclui-se que a gestão escolar se assumida com consciência de sua inserção e atuação técnica, política e social, poderá ser uma oportunidade para a melhoria da educação. De acordo com (RIOS, 2011) o que não é pode vir a ser. O possível ainda não está pronto, deve ser construído.

\section{REFERÊNCIAS}

BARDIN, Laurence. Análise de conteúdo. Tradução de Luis A. Reto e Augusto Pinheiro. Lisboa: Capa de Edições 70, 1977.

CURY, Carlos Roberto Jamil. Gestão democrática da educação: exigências e desafios. Revista Brasileira de Política e Administração da Educação - RBPAE, São Bernardo do Campo, v. 18, n. 2, jul./dez. 2002. Disponível em:<http://seer.ufrgsbr/index.php/rbpae/issue/ view/1557 >. Acesso em: 02 out.2013.

DEMO, Pedro. Habilidades e competências no século XXI. 3.ed, Porto Alegre: Mediação, 2012.

LIBÂNEO. Jose Carlos. Organização e gestão da escola: teoria e prática $6^{a}$ edição. rev e ampl. São Paulo: Heccus Editora. 2013.

LUCK. Gestão educacional: uma questão paradigmática. Série Cadernos de gestão. Vol.1, Petrópolis, RJ. Vozes, 2006.

FERREIRA, Naura Syria Carapeto. Formação continuada e gestão da educação no contexto da "cultura globalizada", São Paulo: Cortez, 2007.

MORAES, Roque; GALIAZZI, M. C. Análise textual discursiva. Ijui, RS, Unijuí Editora, 2007.

PARO, Vitor Henrique. Administração escolar: introdução crítica. 17. ed. rev. e ampli. São Paulo: Cortez, 2012.

RAMOS, Marise Nogueira. A pedagogia das competências: autonomia ou adaptação? São Paulo: Cortez editora, 2001.

RIOS, Teresinha Azeredo. Ética e competência. 20. ed., São Paulo: Cortez,2011. 
RIO GRANDE DO SUL. Lei no $\mathbf{1 3 . 9 9 0}$, de 15 de maio de 2012. (publicada no DOE n. .094 , de 16 de maio de 2012). Introduz modificações na Lei n.. 10.576 , de 14 de novembro de 1995. Dispõe sobre a Gestão Democrática do Ensino Público e dá outras providências. Disponível em: http://www.al.rs.gov.br/filerepositoryrepLegis /arquivos/13.990.pdf. Acesso em 10 dez. 2013.

Secretaria Estadual da Educação. Departamento de Planejamento. Censo Escolar da Educação Básica 2013. Porto Alegre, jan. 2014. Disponível em: <http:// www.educacao.rs.gov.br/dados/estatisticas_2013.pdf>. Acesso em: 25 jan. 2014.

SILVA, Maria Abádia da Silva. Qualidade social da educação pública: algumas aproximações. Caderno CEDES, Campinas, vol. 29, n.78, p.216-226, maio/ago 2009.

\footnotetext{
' Universidade do vale do Sinos - UNISINOS

Andreana.haas@hotmail.com
} 